\title{
Selección de bacterias ácido lácticas del queso artesanal de leche de cabra de Coahuila para su uso como cultivos iniciadores
}

RESUMEN

El estado de Coahuila, México, se caracteriza por la producción de queso artesanal elaborado a partir de leche de cabra. Este estudio se enfocó en el aislamiento, identificación y caracterización de bacterias ácido lácticas (BAL) presentes en este tipo de queso para usarlas como cultivo iniciador. Durante la investigación, se llevó a cabo el aislamiento e identificación de las BAL, caracterizándolas bajo pruebas bioquímicas tales como actividad acidificante, capacidad de inhibición, producción de $\mathrm{CO}_{2}$ y producción de aromas, y se seleccionaron aquellas que presentaron mejores características en las pruebas mencionadas anteriormente. Las BAL seleccionadas fueron preparadas para ser inoculadas en leche pasteurizada de cabra $y$, posteriormente, en la elaboración del queso. Los quesos se evaluaron mediante una prueba sensorial empleando la prueba diferencia de control, los resultados mostraron que los quesos enriquecidos con BAL presentaron características sensoriales globales diferentes al queso de cabra sin adición

Palabras clave: leche cruda; cuajo; pasteurización; patógenos; ácido láctico; evaluación sensorial.

Keywords: raw milk; rennet; pasteurization; pathogens; lactic acid; sensory evaluation.

Recibido: 23 de febrero de 2017, aceptado: 11 de septiembre de 2017

* Departamento de Ciencia y Tecnología de Alimentos, División de Ciencia Animal, Universidad Autónoma Agraria Antonio Narro. Calzada Antonio Narro No. 1923, Col. Buenavista, C. P. 25315, Saltillo, Coahuila, México. Correo electrónico: narvaez_lili@hotmail.com; myke1380@ hotmail.com; francisco.hdezc@gmail.com; mildred.flores@uaaan.mx; gabymtz70@gmail.com; scro7@hotmail.com

$凶$

Autor para correspondencia de BAL. Por tanto, las BAL seleccionadas podrían ser empleadas como cultivos iniciadores.

ABSTRACT

The state of Coahuila, Mexico, is characterized by the production of artisanal cheese made from goat's milk. This study focuses on isolation, characterization and selection of lactic acid bacterias (LAB) from artisanal goat cheese for their use as starter cultures. During this reseach, the isolation and identification of BAL were carried out characterizing them under biochemical tests, such as acidifying activity, inhibition capacity, $\mathrm{CO}_{2}$ and aroma production, selecting those that presented better characteristics of the tests described above. Selected BAL were prepared to be inoculated in pasteurized goat milk and later in the cheese making. The cheeses were evauated by control difference. A sensory test result showed similar characteristics in goat cheese. Therefore, the selected BAL are useful as starter cultures.

INTRODUCCIÓN

Se consideran quesos artesanales los elaborados con leche bronca, sin la adición de cepas iniciadoras. Sin embargo, se consideran alimentos que pueden llegar a alterar la salud del consumidor, debido a la flora microbiana patógena existente en la leche cruda, que puede persistir al no recibir ningún tratamiento térmico para disminuir su carga (Alvarado Rivas, Chacón Rueda, Rojas, Guerrero Cárdenas, \& López Corcuera, 2007). Las BAL son microorganismos responsables de proporcionar las características típicas como sabor y textura en quesos artesanales, que se ven afectadas al recibir 
un tratamiento térmico como la pasteurización, debido a la destrucción de la microflora natural de la leche cruda; sin embargo, este proceso se considera esencial para satisfacer las normas de inocuidad de los alimentos (Ramos-lzquierdo, Bautista-Muñoz, Aranda-lbáñez, \& Izquierdo-Reyes, 2009; Serpa Fajardo, Pérez de la Ossa, \& Hernández R., 2016). En la actualidad las BAL son utilizadas sobre todo en las fermentaciones, debido a las propiedades que brindan al ser aplicadas en diversos alimentos (Martín del Campo M., Gómez H., \& Alaníz de la O., 2008). Hoy día los cultivos iniciadores son preparaciones de microorganismos vivos, con el fin de hacer uso de su metabolismo microbiano, principalmente utilizados en la industria alimentaria. Estos tipos de cultivos se encuentran formados principalmente por BAL; entre los géneros más comunes destacan Lactococcus, Lactobacillus y Leuconostoc, ya que su principal función es la producción de ácido láctico (Alvarado Rivas et al., 2007).

En el queso de cabra venezolano artesanal se ha identificado a Leuconostoc mesenteroides como uno de los principales contribuyentes de las características de este producto, fresco y de color blanco, que se define por ser elaborado con leche cruda de cabra y la adición de suero fermentado, a modo de cultivo iniciador; por lo anterior, es un producto desigual en cuanto a propiedades físicas y químicas (Mago, Sanabria, Cova, Alvarado, \& Durán, 2015). De igual manera, el queso artesanal de cabra producido en las comunidades del sureste de Coahuila se elabora a partir de leche cruda de cabra y como agente coagulante el abomaso fermentado en suero de leche. Las anteriores condiciones le otorgan a este queso un sabor característico, muy apreciado gracias a las BAL nativas; no obstante, a pesar de su sabor, es un producto que está perdiendo presencia en el mercado local debido a las alteraciones a la salud que ocasiona en los consumidores. Por lo anterior, si se emplean BAL nativas del queso artesanal de cabra como cultivos iniciadores y se agregan a la leche pasteurizada, se podría obtener un producto inocuo que rescate el sabor característico del queso artesanal, sin poner en riesgo la salud del consumidor.

El objetivo de este trabajo fue aislar BAL nativas de muestras de leche, cuajo y queso artesanal de cabra del sureste de Coahuila, seleccionando las cepas microbianas que mejor respondieron a diferentes pruebas bioquímicas para la elaboración de un cultivo iniciador, el cual permitió la producción de diferentes quesos a partir de leche pasteurizada de cabra, con la idea de obtener quesos de cabra con características sensoriales globales distintas al queso de leche pasteurizada de cabra sin adición de cultivos iniciadores.

\section{MATERIALES Y MÉTODOS}

\section{Aislamiento de las BAL}

Las BAL se aislaron a partir de muestras de leche, cuajo y queso de diferentes queserías ubicadas en los municipios Arteaga y Saltillo, Coahuila. Para aislar las bacterias se realizaron diluciones seriadas $(10$ $2,10^{-3}, 10^{-4}$ ), sembradas por duplicado mediante el método de superficie en placa en medio agar Man, Rogosa y Sharpe (MRS), incubadas de 24 a $48 \mathrm{~h}$ y $35{ }^{\circ} \mathrm{C}$ en condiciones de anaerobiosis. Al observar crecimiento fueron seleccionadas diferentes colonias de cada dilución de las diferentes muestras. Las colonias seleccionadas fueron sembradas en agar MRS por estría cruzada e incubadas en condiciones de anaerobiosis a $35^{\circ} \mathrm{C}$ por $24 \mathrm{~h}$ para su posterior identificación (Tuncer, 2009).

\section{Identificación de las BAL}

A cada una de las colonias aisladas se le realizó la prueba de tinción Gram propuesta por Cristian Gram en 1884, con el fin de seleccionar las bacterias Gram positivas (López-Jácome et al., 2014); así como también la prueba de la catalasa, con el fin de obtener bacterias catalasa negativa, característica propia de las BAL (Ruíz Ruíz, 2010). Posterior a esto, las cepas fueron conservadas en caldo MRS a congelación $\left(-20^{\circ} \mathrm{C}\right)$, empleando la metodología de Sánchez, Corrales, Corrales y Oñate-Sánchez (2005), para su uso en las pruebas posteriores.

\section{Caracterización de las BAL}

Después de la conservación, las cepas de BAL fueron reactivadas en tubos con $2 \mathrm{ml}$ de caldo MRS estéril agregando $1 \% \mathrm{v} / \mathrm{v}$ del inóculo en conservación 10.02 $\mathrm{ml}$ ) e incubadas a $35^{\circ} \mathrm{C}$ durante $24 \mathrm{~h}$ en anaerobiosis. Posteriormente, cada una de las cepas identificadas como BAL fueron sometidas a las siguientes pruebas:

Actividad acidificante. Como medio de crecimiento se empleó leche light (leche en polvo comercial baja en grasa preparada de acuerdo con las instrucciones del fabricante) en frascos de $50 \mathrm{ml}$, esterilizada a $121{ }^{\circ} \mathrm{C}$ por $25 \mathrm{~min}$. Se inoculó $1 \% \mathrm{v} / \mathrm{v}$ $(0.50 \mathrm{ml})$ del microorganismo reactivado, incubado bajo las mismas condiciones descritas anteriormente. La acidez fue determinada a las 0, 6, 12 y $24 \mathrm{~h}$ de 
incubación, por triplicado para cada cepa. El ácido láctico se determinó por medio de titulación con $\mathrm{NaOH}$ al $1 \mathrm{~N}$ y fenolftaleína como indicador, y se obtuvieron resultados en porcentaje de acidez (Guerrero, Muset, \& Pacheco, 1997).

Capacidad de inhibición de bacterias patógenas. Las bacterias patógenas empleadas fueron Salmonella ssp., S. aureus y E. coli, esta metodología se adaptó de acuerdo con lo descrito por Vinderola et al. (2008), utilizando la técnica de difusión en hoyo con tres repeticiones por cepa, se obtuvieron lecturas de diámetros de halos de inhibición en cm.

Producción de $\mathrm{CO}_{2}$. Tubos Pyrex con $5 \mathrm{ml}$ de caldo MRS estéril y campanas Durham fueron inoculados con $1 \% \mathrm{~V} / \mathrm{v}$ de las cepas de BAL reactivadas, se incubaron en las mismas condiciones anteriormente citadas, este procedimiento se realizó por triplicado para cada cepa (Ramos-Izquierdo et al., 2009).

Producción de aromas en leche. Se inoculó $1 \%$ v/v de cada cepa reactivada en tubos con $5 \mathrm{ml}$ de leche light estéril (preparada conforme las instrucciones del fabricante), los tubos se llevaron a incubación a $35^{\circ} \mathrm{C}$ por $24 \mathrm{~h}$. Con el fin de seleccionar las cepas capaces de producir aromas típicos lácteos, las leches fermentadas por las cepas contenidas en tubos fueron evaluadas sensorialmente por tres jueces expertos. Cada uno de los jueces evaluó el aroma producido, seleccionaron las que presentaron aromas típicos a lácteos como yogurt, mantequilla, queso, crema, etc. (Heredia, 2011).

\section{Preparación de BAL para manufactura de queso pasteurizado de leche de cabra}

Se seleccionaron cepas que presentaron producción de ácido láctico y capacidad alta de inhibición de bacterias patógenas y que fueran productoras de olores lácticos característicos. Se realizaron las siguientes curvas para medir las fases de crecimiento:

Curva de calibración. Se emplearon matraces con $70 \mathrm{ml}$ de caldo MRS inoculados con $1 \%$ de cultivo fresco de las cepas. Se incubaron a $35^{\circ} \mathrm{C}$ y se tomaron muestras a las 2, 4, 8 y $12 \mathrm{~h}$, las cuales se leyeron en espectrofotómetro de rango visible a $600 \mathrm{~nm}$, utilizando como blanco caldo RMS estéril. Se elaboraron diluciones seriadas en cada tiempo de incubación para disminuir la población celular, las diluciones fueron plaqueadas con el fin de contabilizar la UFC. Se tomó en cuenta la absorbancia $(Y)$, así como las UFC/ml (X) de cada lectura (Díaz, 2011).
Curva de crecimiento. Se utilizaron matraces con 50 $\mathrm{ml}$ de caldo MRS inoculado con $1 \% \mathrm{v} / \mathrm{v}$ de las cepas. Se incubaron a $35^{\circ} \mathrm{C}$ y se tomaron muestras a las 2,4 , 8 y $12 \mathrm{~h}$, las cuales se leyeron en espectrofotómetro de rango visible a $600 \mathrm{~nm}$, utilizando como blanco caldo RMS estéril. Y posteriormente las UFC/ml correspondientes a cada densidad óptica. Los resultados fueron graficados para visualizar el crecimiento que presentó cada una de las cepas seleccionadas (Díaz, 2011). Las concentraciones de UFC/ml presentadas por cada cepa al inicio de la fase estacionaria fueron empleadas para llevar a cabo la inoculación de la leche de cabra y posteriormente la elaboración de queso.

\section{Elaboración de queso de leche pasteurizada de cabra utilizando las BAL seleccionadas}

Utilizando las cepas seleccionadas QJ2 y QR2 se elaboraron cuatro quesos: uno con la cepa QJ2, otro con $Q R 2$, uno combinado con ambas cepas (COM) y uno control (testigo), sin bacterias agregadas. La leche de cabra se pasteurizó a $72{ }^{\circ} \mathrm{C}$ por 1 min, seguido de un enfriamiento rápido a 40 ${ }^{\circ} \mathrm{C}$, posteriormente, la leche se inoculó con $1 \% \mathrm{v} / \mathrm{v}$ de las cepas seleccionadas, QR2 (9.0 log UFC/ml) y QJ2 (9.0 log UFC/ml ). En la elaboración del COM la leche se inoculó con $0.5 \% \mathrm{v} / \mathrm{v}$ de cada cepa. Para lograr la coagulación de la leche se utilizó $1 \mathrm{ml}$ de cuajo artificial (Normex) por cada 10 I de leche, se permitió actuar por 10 min para proceder al corte y desuerado. Se agregaron $30 \mathrm{gr}$ de $\mathrm{NaCl}$ por cada 10 I de leche, la masa fue moldeada en aros metálicos, se maduró en refrigeración a $4{ }^{\circ} \mathrm{C}$ durante toda la noche (Ramos-Izquierdo et al., 2009).

\section{Evaluación sensorial del queso de cabra}

Los productos fueron evaluados mediante la prueba de diferencia de control, con el objetivo de identificar diferencias sensoriales globales entre los diferentes quesos comparadas contra un control (testigo). De tal manera que se midió el queso QJ2 contra el control, el QR2 contra el control, el COM contra el control; además esta prueba contempla un par placebo; es decir, se midió la diferencia del control contra sí mismo. Las diferencias fueron evaluadas por un total de 20 jueces semientrenados en una escala del 0 (No hay diferencia) al 9 (Diferencia muy grande), de acuerdo con la metodología de Hernández Montes (2007).

\section{Análisis estadísticos}

Los resultados obtenidos de la actividad acidificante e inhibición de bacterias patógenas fueron analiza- 
IIVESTIGACIÓn Y CIERCIA DE LA UחIVERSIDAD AUTÓNOTH

DE RGUASCALIERTES dos con un diseño completamente al azar mediante comparación de Tukey, mientras que los resultados de la prueba sensorial del queso de cabra se analizaron mediante análisis de varianza con diseño de bloques completamente al azar $(P \leq 0.05)$.

\section{RESULTADOS}

\section{Aislamiento e identificación de las BAL}

Se identificaron 21 cepas positivas a la tinción de Gram y negativas a la prueba de la catalasa, con un periodo de crecimiento menor a $24 \mathrm{~h}$.

\section{Caracterización de las BAL}

Actividad acidificante. Durante la acidificación de las bacterias, los rangos de ácido láctico alcanzados por las 21 cepas fueron de $0.26-0.45 \%$ a las $12 \mathrm{~h}$, $0.35-0.6 \%$ a las $24 \mathrm{~h}$ y $0.47-0.94 \%$ a las $48 \mathrm{~h}$ (figuras 1, 2 y 3). Fueron QC4, QR1, QR2, CC3 QR3 y CJ4 las cepas que presentaron mayor porcentaje de ácido láctico al finalizar el periodo de incubación para esta prueba con 0.94.0.92, 0.89, 0.89, 0.85 y $0.85 \%$, respectivamente $(P>0.05)$, como puede apreciarse en la figura 3.

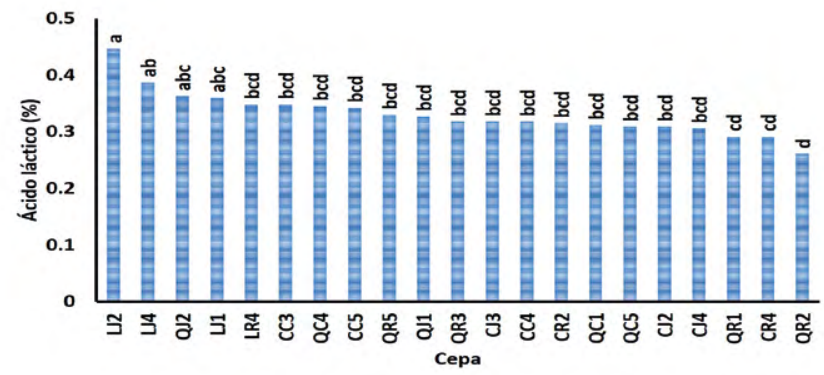

Figura 1. Actividad acidificante de las BAL a las $12 \mathrm{~h}$ de incubación. Elaboración propia.

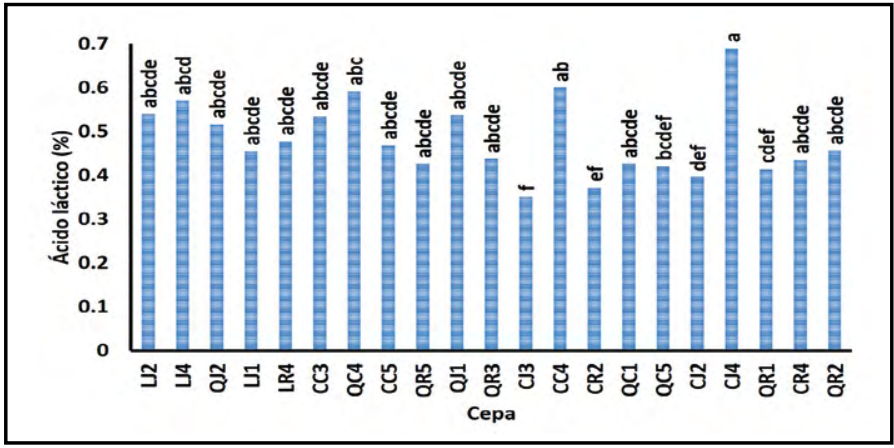

Figura 2. Actividad acidificante de las BAL a las $24 \mathrm{~h}$ de incubación. Elaboración propia.

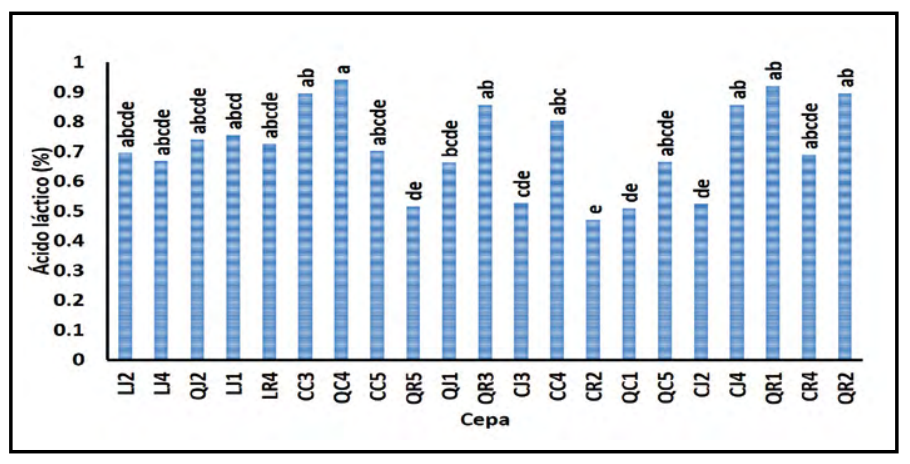

Figura 3. Actividad acidificante de las BAL a las 48 h de incubación. Elaboración propia.

Capacidad de inhibición de bacterias patógenas. La inhibición de las cepas de BAL frente a Salmonella se presentó en un rango de 1.13-1.76 cm de diámetro, CJ2 y QR2 presentaron la mayor inhibición ante este patógeno con 1.76 y $1.73 \mathrm{~cm}$ de diámetro, respectivamente (figura 4). Los rangos de inhibición frente a E. coli se presentaron en $0.93-1.60 \mathrm{~cm}$ de diámetro, QJ2 y QR1 con diámetros de 1.60 y $1.60 \mathrm{~cm}$, respectivamente, presentaron la mayor inhibición (figura 5), mientras que frente a Stafilococcus aureus, las 21 cepas de BAL se comportaron estadísticamente similar $(P>0.05)$, inhibiendo en un rango de 1.46-1.83 $\mathrm{cm}$ de diámetro (figura 6 ).

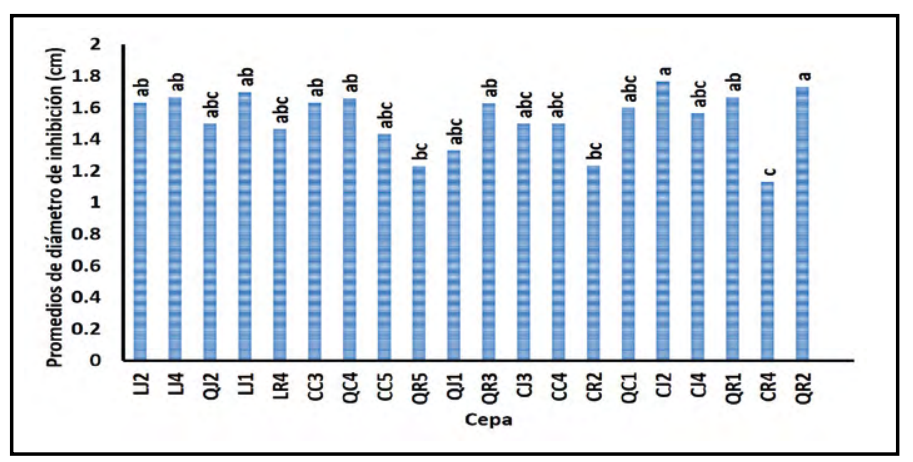

Figura 4. Capacidad inhibitoria de las BAL frente a Salmonella. Elaboración propia.

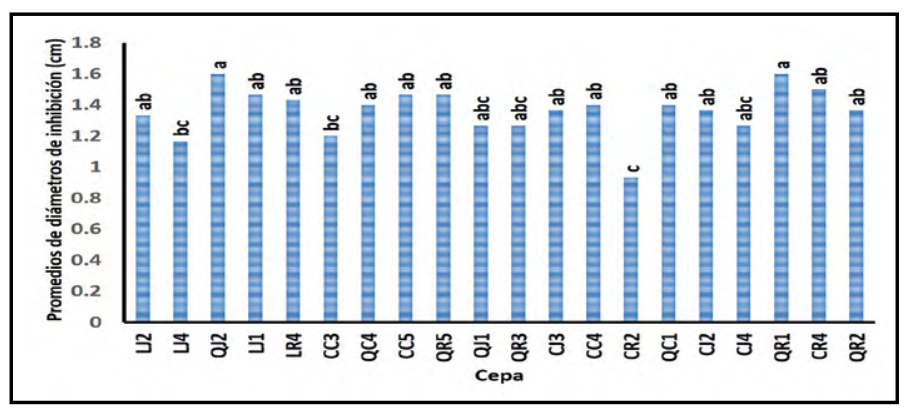

Figura 5. Capacidad inhibitoria de las BAL seleccionadas frente a Stafilococcus aureus.

Elaboración propia. 


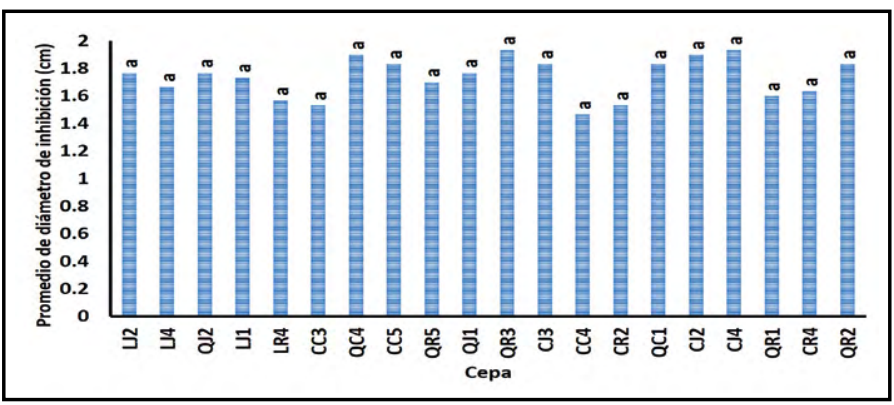

Figura 6. Capacidad inhibitoria de las BAL frente a Escherichia coli. Elaboración propia.

Producción de $\mathrm{CO}_{2}$. Ninguna de las 21 cepas de BAL registró producción de gas.

Producción de aromas en leche. De las 21 cepas evaluadas, 17 produjeron aromas agradables, de estas, sólo seis (LJ2, QR2, CC4, LJ4, QJ2 y CR4) presentaron aromas con notas lácticas.

Preparación de BAL para elaboración de queso de leche pasteurizada de cabra

Fueron seleccionadas las cepas QR2 y QJ2 para la elaboración de los productos, tomando en cuenta su desempeño en cada una de las pruebas anteriores.

Curva de calibración. Se obtuvo una concentración en un periodo final a las $12 \mathrm{~h}$ de $9.4 \mathrm{UFC} / \mathrm{ml}$ con una $R^{2}$ de 0.96 para $Q R 2$, mientras que QJ2 presentó una concentración final de $9.5 \mathrm{UFC} / \mathrm{ml}$ a las $12 \mathrm{~h}$ de incubación y una $\mathrm{R}^{2}$ de 0.94 .

Curva de crecimiento. En la curva de crecimiento, para QR2 (figura 7) en un tiempo de $9 \mathrm{~h}$ y una concentración de $9.04 \mathrm{log} \mathrm{UFC} / \mathrm{ml}$, se puede distinguir el final de la fase de crecimiento e inicio de

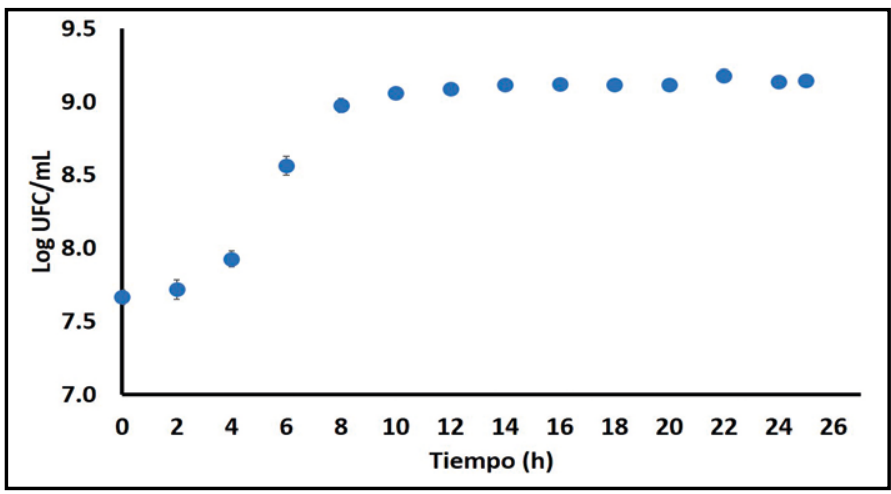

Figura 7. Curva de crecimiento de QR2.

Elaboración propia. la fase estacionaria; mientras que para QJ2 (figura 8) en un tiempo de $10 \mathrm{~h}$, con una concentración de 9 log UFC/ml, se aprecia el mismo comportamiento.

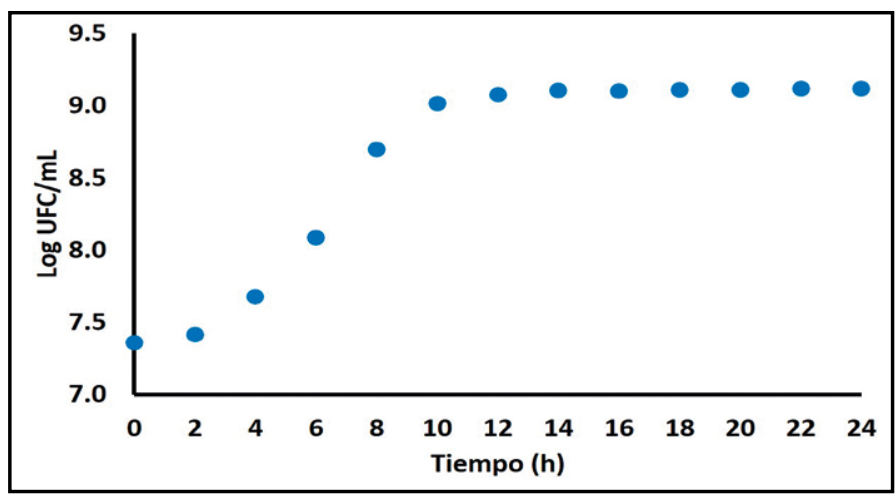

Figura 8. Curva de crecimiento de QJ2.

Elaboración propia.

Elaboración de queso de leche pasteurizada de cabra utilizando las BAL seleccionadas

Para cada versión de queso, a partir de las cepas seleccionadas, se elaboraron tres unidades de $300 \mathrm{~g}$ cada una; al primer tipo de queso se inoculó la cepa QJ2 (figura 9), al segundo la cepa QR2, al tercero las dos cepas anteriores en combinación, nombrado como COM y el cuarto fue el testigo elaborado únicamente con leche de cabra pasteurizada, sin la adición de cepas.

\section{Evaluación sensorial del queso de cabra}

Los quesos QJ2 y COM obtuvieron promedios de 5.15 y 5.10 , respectivamente, en la escala de diferencia con respecto al control $(P<0.05)$, lo anterior indica

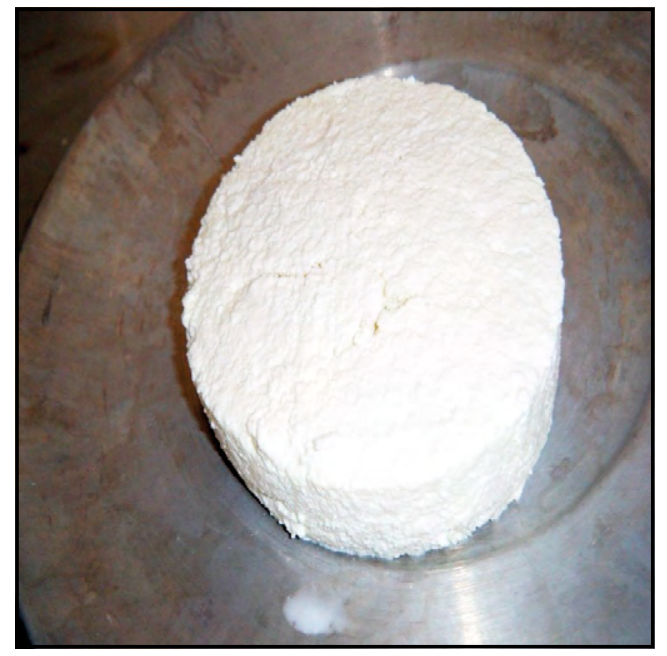

Figura 9. Queso elaborado con leche pasteurizada de cabra adicionada con BAL (QJ2). Fotografía de Liliana Narváez Guillén. 


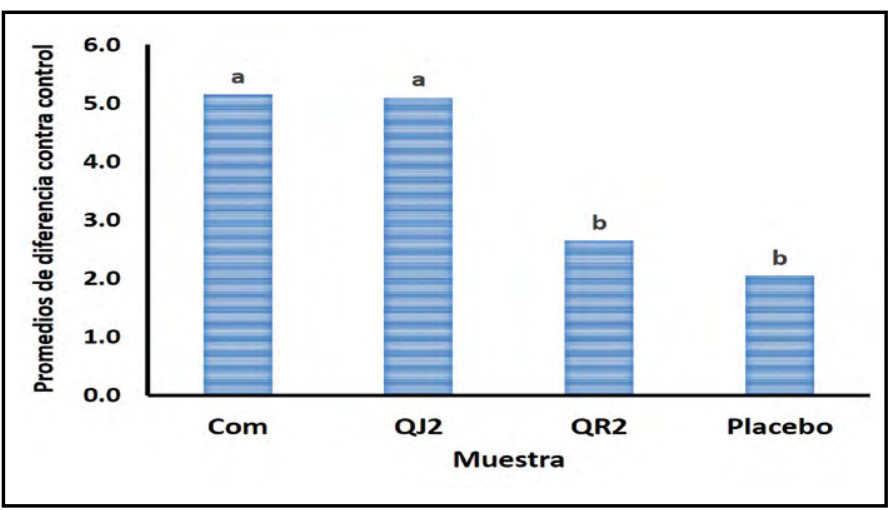

Figura 10. Medias de la diferencia de las muestras con respecto al control.

Elaboración propia.

que mientras mayor es la diferencia de una muestra con respecto al control (queso sin BAL añadidas), las características sensoriales globales tales como sabor, olor, textura y consistencia, tambien son diferentes. Por otra parte, los QR2 y placebo, con promedios en la escala de diferencia con respecto al control de 2.65 y 2 , respectivamente $(P<0.05)$, fueron evaluados por los jueces como las muestras con las características sensoriales globales afines al control; es decir, que en el caso del QR2 no hubo impacto en el desarrollo de características sensoriales globales en el queso, mientras que en la muestra placebo (control contra control), dado que es la misma muestra, se esperaba una calificación baja en la escala; es decir, no deberían encontrarse diferencias (figura 10).

\section{DISCUSIÓN}

La capacidad de acidificación de las BAL es criterio importante para la elaboración de quesos, un medio ácido reduce la posibilidad de crecimiento microbiano no deseable, además las cepas que llegan a producir un medio ácido en corto periodo de tiempo se consideran viables para procesos en fermentación de productos lácteos, asi como para ser empleados como cultivos iniciadores primarios (Tuncer, 2009). En este estudio se encontraron cepas que durante las primeras $12 \mathrm{~h}$ de acidificación mostraron incrementar el contenido de ácido láctico en el medio a tasas de 0.45 y $0.39 \%$, tal es el caso de LJ2 y LJ4, respectivamente; sin embargo, a las $48 \mathrm{~h}$ de acidificación la mayor producción del metabolito lo produjeron QC4, QR1, QR2, CC3 QR3 y CJ4, con valores de 0.94, 0.92, 0.89, $0.89,0.85$ y $0.85 \%$, repectivamente $(P<0.05)$; estos valores difieren de lo reportado por Nieto-Arribas, Poveda, Palop y Cabezas (2008), quienes en su estudio para seleccionar cultivos nativos para la manufactura de queso manchego, reportan a los géneros Lactobacillus y Lactococcus como los mejores productores de ácido láctico, con un rango de $0.18-0.79 \%$ para Lactobacillus y de $0.16-0.27 \%$ para Lactococcus. Las BAL aisladas del queso de cabra presentan una mayor actividad acidificante, característica que influye en la capacidad de inhibición contra patógenos.

El ácido láctico es considerado un metabolito antimicrobiano debido a la capacidad de inhibir a bacterias patógenas (Ramírez Cuenca, 2005). Los resultados de este trabajo permitieron identificar que las cepas que mayor producción de ácido láctico presentaron, también lograron inhibir en mayor cantidad a las bacterias patógenas en estudio. Estas cepas fueron QR2 y QJ2 con 0.9 y $0.74 \%$ de producción de ácido láctico a las $48 \mathrm{~h}$, respectivamente, así como 1.36 y $1.6 \mathrm{~cm}$ de diámetro de inhibición para E. coli y para Salmonella, 1.73 y $1.5 \mathrm{~cm}$ de diámetro de inhibición, respectivamente. Aguilar y Klotz (2011) mencionan que cocultivos de L. plantarum han logrado inhibir a $E$. coli hasta tres ciclos logarítmicos. La inhibición de E.coli en este estudio, si bien no se conoce en ciclos logarítmicos, se puede considerar como aceptable y de interés para posteriores estudios.

En este estudio, las 21 cepas de BAL mostraron un comportamiento semejante ante la inhibición de Stafilococcus aureus, con un rango de 1.4-1.83 $\mathrm{cm}$. Un estudio semejante por Martín del Campo M., Gómez H. y Alaníz de la O (2008) reportó inhibición de Stafilococcus aereus por siete cepas de BAL aisladas de quesos frescos; las cepas que mostraron actividad antagónica positiva fueron las aisladas de queso panela, adobera y fresco, la técnica empleada fue la de picadura, y se reporta en $\mathrm{mm}$ de inhibición. Las cepas de BAL aisladas del queso de cabra en este estudio son más eficientes contra este patógeno, probablemente porque además de tener actividad acidificante suficiente, podrían estar generando bacteriocinas capaces de inhibir crecimiento bacteriano.

Las bacterias homofermentativas son las que obtienen como producto final ácido láctico de un 90-99\%, los géneros de Lactococcus, Pediococcus, Enterococcus, Vagococcus, Streptococcus y junto con algunos Lactobacillus, pertenecen a este grupo (Parra Huertas, 2010). El tipo de fermentación final de las BAL empleadas en el presente trabajo se conside- 


\section{IIVESTIGACIÓn Y CIECEIA DE LA UחIVERSIDAD AUTÓNOMA DE AGUASCALIERTES}

ró homofermentativo, debido a que no se presentó desarrollo de $\mathrm{CO}_{2}$ en ninguna de las 21 cepas. Esta característica es propia de la mayor parte de la flora bacteriana acidificante de la leche (Villegas de Gante, 2004), lo que le permite formación de ácido láctico como producto mayoritario y que este, a su vez, inicia una fermentación rápida en la leche ejerciendo además un efecto de preservación. Asimismo, las BAL homofermentativas presentan capacidad proteolítica que forma péptidos amargos que impactan en el sabor y olor del queso como resultado de la conversión de aminoácidos como metionina, leucina y fenilalanina (Parra Huertas, 2010).

Los principales aromas desarrollados por las cepas aisladas en este estudio identificados por jueces expertos fueron notas de yogurt y productos fermentados. Nieto-Arribas, Seseña, Poveda, Palop y Cabezas (2009) mencionan en su estudio que los principales aromas desarrollados por las BAL después de siete días de incubación pertenecen a yogurt y mantequilla, lo que coincide en las notas aromáticas con las de este estudio. Alvarado Rivas et al. (2007) demostraron que las cepas aisladas de Lactobacillus y Lactococcus a partir de un queso artesanal, al ser inoculadas en quesos experimentales elaborados a partir de leche pasteurizada, son equivalentes a las que se elaboran con leche cruda, y que estas bacterias son las responsables de proporcionar las características particulares del queso.

Alvarado Rivas et al. (2007) demostraron que al inocular cepas de Lactobacillus y Lactococcus aisladas de un queso artesanal en quesos experimentales elaborados a partir de leche pasteurizada, no existen diferencias significativas en atributos de sabor, textura y color con respecto a un queso control elaborado con leche cruda. Esto indica que las cepas autóctonas agregadas logran desarrollar características sensoriales semejantes a las que tendría uno elaborado a partir de leche cruda. En el mismo contexto, los elaborados con las cepas QJ2 y el combinado (COM) de este estudio, presentaron di- ferencias estadísticas en cuanto a las caracteristicas globales (sabor, olor, textura y consistencia) con respecto al control elaborado con leche pasteurizada sin cepas añadidas, lo cual deja de manifiesto que existen características presentes en los quesos QJ2 y $C O M$ que son atribuidas a las cepas adicionadas.

Por otra parte, Mago et al. (2015) en un estudio de aceptabilidad, encontró que un queso elaborado a partir de leche pasteurizada e inoculado con bacterias autóctonas (Leuconostoc meseteroides) presentó mayor aceptabilidad frente a uno manufacturado en las mismas condiciones del anterior, pero inoculado con una cepa comercial (Lactococcus lactis); dichos resultados ponen de manifiesto las ventajas en las capacidades metabólicas de las BAL autóctonas con respecto a las cepas comerciales. Lo anterior es una alternativa para obtener quesos de mejor calidad sanitaria sin afectar las características sensoriales propias de un queso artesanal.

\section{CONCLUSIONES}

Los quesos elaborados a partir de leche de cabra pasteurizada e inoculados con las cepas QJ2 y en combinación con QJ2 y QR2, según la evaluación sensorial, presentaron características globales estadísticamente diferentes a las del queso pasteurizado sin adición de cepas (control). Por tanto, las cepas aisladas en este estudio pueden ser empleadas como cultivos iniciadores, y son adecuadas para producir queso de leche de cabra con características semejantes al artesanal, empleando leche pasteurizada. Sin embargo, si se desea conocer dichas caracteristicas de manera cualitativa y cuantitativa, es necesario realizar un estudio sensorial descriptivo, pues con la prueba sensorial aplicada en este estudio sólo se determinan diferencias globales entre productos. Adicionalmente, son necesarios estudios genéticos para identificar género y especie de las cepas seleccionadas como BAL en el presente trabajo. 
- Aguilar, C., \& Klotz, B. (2011). Inhibición del crecimiento de Escherichia coli por bacterias ácido lácticas: presencia de quórum sensing? Alimentos hoy. Revista de la Asociación Colombiana de Ciencia y Tecnología de Alimentos, 13(13), 18-26.

- Alvarado Rivas,, C., Chacón Rueda, Z., Rojas, J. O., Guerrero Cárdenas, B., \& López Corcuera, G. (2007). Aislamiento, identificación y caracterización de bacterias ácido lácticas de un queso venezolano ahumado andino artesanal. Su uso como cultivo iniciador. Revista Científica, 17(3), 301-308.

- Díaz, C. (2011). Adherencia y colonización de Pseudomonas fluorescens sobre sustratos sólidos: Influencia de la topografía y composición química de la superficie (Tesis doctoral). Universidad Nacional de la Plata, Buenos Aires.

- Guerrero, L., Muset, G., \& Pacheco, L. (1997). Evaluación de las actividades enzimáticas de cultivos comerciales usados para la elaboración de quesos. Revista científica FCV-LUZ, 7(3), 209214.

- Heredia, P. (2011). Caracterización del proceso de producción del queso cocido artesanal y de las principales bacterias ácido lácticas generadoras de aroma (Tesis de maestría). Centro de Investigación en Alimentación y Desarrollo, Hermosillo, Sonora, México.

- Hernández Montes, A. (2007). Evaluación sensorial de productos agroalimentarios. Texcoco, Estado de México: Universidad Autónoma de Chapingo.

- López-Jácome, L. E., Hérnadez-Durán, M., Colín-Castro, C. A., Ortega-Peña, S., Cerón-González, G., \& Franco-Cendejas, R. (2014). Las tinciones básicas en el laboratorio de microbiología. Investigación en Discapacidad, 3(1), 10-18.

- Mago, Y., Sanabria, N., Cova, A., Alvarado, C., \& Durán, L. ( 2015). Maduración de queso de cabra con cepa autóctona de Leuconostoc mesenteroides aislada de queso artesanal. Revista de la Facultad de Ciencias Veterinarias, 56(1), 3-9.

- Martín del Campo M., C. I., Gómez H., H. E., \& Alaníz de la O, R. (2008). Bacterias ácido lácticas con capacidad antagónica y capacidad bacteriocinogénica aislada de quesos frescos. E-Gnosis, 6, 1-17.

- Nieto-Arribas, P., Poveda, J. M., Palop, Ll., \& Cabezas, L. (2008). Comparative study of methods for the determination of proteolytic activity in lactic acid bacteria and selection of an autochthonous starter to manufacture manchego cheese. Milchwissenschaft, 63, 61-63.
- Nieto-Arribas, P., Seseña, S., Poveda, J. M., Palop, LI., \& Cabezas, L. (2009). Genotypic and technological characterization of Lactococcus lactis isolates involved in traditional processing of artisanal Manchego cheese. Journal of Applied Microbiology, $107(5), 1505-1517$.

- Parra Huertas, R. A. (2010). Bacterias ácido lácticas: Papel funcional en los alimentos. Biotecnología en el Sector Agropecuario y Agroindustrial, 8(1), 93-105.

- Ramírez Cuenca, M. S. (2005). Actividad inhibitoria de cepas de bacterias ácido lácticas frente a bacterias patógenas y deterioradoras de alimentos (Tesis de licenciatura). Universidad Autónoma del Estado de Hidalgo, México.

- Ramos-lzquierdo, B., Bucio-Galindo, A., Bautista-Muñoz, C., Aranda-lbáñez, E., \& Izquierdo-Reyes, F. (2009). Aislamiento, identificación y caracterización de bacterias ácido lácticas para la elaboración de queso crema tropical. Universidad y Ciencia Trópico Húmedo, 25(2), 159-171.

- Ruíz Ruíz, F. (2010). Pruebas bioquímicas: Catalasa [Fragmento de manual en pdf]. Manual de Prácticas de Biología de Procariotas (Práctica 11). Recuperado el 21 de febrero de 2017, de https://biolprocariotas.files.wordpress.com/2010/03/ pract-1 12.pdf

- Sánchez, L., Corrales, R., Corrales, L., \& Oñate-Sánchez, L. (2005). Evaluación de la congelación para conservación de especies autóctonas bacterianas. NOVA-PUBLICACIÓN CIENTÍFICA, 3(4), 21-29.

- Serpa Fajardo, J. G., Pérez de la Ossa, T. I., \& Hernández R., Elvis J. (2016). Effect of pasteurization and starter cultures on physicochemical and microbiological properties of costeño cheese. Revista Facultad Nacional de Agronomía, 69 (2), 80078014.

- Tuncer, Y. (2009). Some technological properties of phenotypically identified enterococci strains isolated from Turkish tulum cheese. African Journal of Biotechnology, 8(24), 7008-7016.

- Villegas de Gante, A. (2004). Tecnologia quesera. Distrito Federal, México: Trillas.

- Vinderola, G., Capellini, B., Villarreal, F., Suárez, V., Quiberoni, A., \& Reinheimer, J. (2008). Usefulness of a set of simple in vitro tests for the screening and dentification of probiotic candidate strains for dairy use. LWT-Food Science and Technology, 41 (9), 1678-1688. 